\title{
DO DIFUSIONISMO ÀS NOVAS PERSPECTIVAS DA EXTENSÃO RURAL: AÇÕES EXTENSIONISTAS EM IBITIARA-BA
}

\author{
ANDRADE, Alvaro Antonio Xavier de. Mestrando em Extensão Rural do Programa de Pós-Graduação em \\ Extensão Rural do Departamento de Economia Rural da Universidade Federal de Viçosa. E-mail: \\ aaxandrade2@hotmail.com. \\ FERREIRA NETO, José Ambrósio; OLIVEIRA, Marcelo Leles Romarco de.; SILVA, Gustavo Bianch.; \\ MOREIRA, Diego Camelo. Universidade Federal de Viçosa.
}

\section{RESUMo}

No presente ensaio apresentamos uma breve descrição do processo histórico da extensão rural no Brasil, do difusionismo e acontecimentos oriundos deste processo. Posteriormente, é feita uma abordagem sobre a nova perspectiva da extensão rural, que busca dar importância aos conhecimentos e saberes tradicionais das comunidades locais, desenvolver melhor integração entre extensionistas e agricultores, procurando melhorar os trabalhos desenvolvidos pelos serviços de Assistência Técnica Rural - ATER, visando alcançar a sustentabilidade dos processos produtivos e satisfazer as expectativas dos agricultores. Em seguida, é apresentada a extensão rural no município de Ibitiara, na Bahia, a partir de um recorte dos trabalhos desenvolvidos por uma equipe, da qual o primeiro autor desse trabalho fez parte como extensionista entre os anos de 2008 e 2011 . Os trabalhos desenvolvidos apontam para o potencial das práticas extensionistas em melhorar as condições socioeconômicas dos agricultores familiares, e diminuir as práticas clientelistas pelo poder público local, bastante comum em pequenos municípios do semiárido, além de potencializar o desenvolvimento sustentável para a região.

Palavras-chave: Extensão rural; Clientelismo; Organização Social.

\section{FROM DIFFUSIONISM TO THE NEW RURAL EXTENSION PERSPECTIVES: EXTENSIONIST ACTIONS IN IBITIARA-BA}

\begin{abstract}
In this essay we present a brief description about the rural extension historical process in Brazil, about diffusionism and findings from this process. Subsequently, it will be presented a new perspective ofrural extension, that searches to value the traditional knowledge of local communities, to develop a better integration of extensionists and family farmers, looking for an improvement in the services of Rural Technical Assistance-RTA, aiming at the sustainability of the productive processes and at the satisfaction of the agricultors' expectation. Next, the rural extension in the Ibitiara City, Bahia, is presented, based on a selection of the activities developed by an extensionist group, of which the first author of this paper was part, between the years 2008 and 2011. The results point to the potential of rural extension practices to improve the socioeconomic conditions of family farmers, and to reduce clientelist practices by local authorities, quite common in semiarid's small towns, and to enhance the sustainable development for the region.
\end{abstract}

KEYwORDs: Rural extension; Clientelism; Social organization. 


\section{INTRODUÇão}

Os trabalhos de extensão rural no país foram implantados no intuito de "modernizar" o campo, aumentar a produtividade das lavouras e melhorar as condições de vida das suas populações. Este processo modernizante, pautado no difusionismo, tinha como premissa o abandono dos conhecimentos tradicionais por parte dos agricultores. Apoiados pelos extensionistas rurais, os agricultores deveriam implantar pacotes tecnológicos atrelados ao crédito rural, visando atingir os objetivos acima citados. O processo difusionista não conseguiu atingir totalmente seus objetivos, visto que as diferenças locais, estruturais, financeiras e tradicionais entre os habitantes do campo fizeram com que parte dos agricultores não acompanhasse o processo de mudança. (COELHO, 2005; FONSECA, 1985; FREIRE, 1992)

Na nova perspectiva adotada para extensão rural, os conhecimentos e saberes tradicionais devem ser respeitados, tornando-se necessário somá-los aos conhecimentos acadêmicos dos agentes de extensão. É dessa forma que se pretende atingir a sustentabilidade e satisfazer as reais necessidades das populações do campo. Nesse viés da ação extensionista, juntamente com a reativação da Secretaria Municipal de Agricultura e Meio Ambiente de Ibitiara em 2008, iniciou-se uma nova fase dos trabalhos de extensão no município.

Ibitiara fica localizada na Chapada Diamantina, no semiárido baiano. A agropecuária é a principal atividade da população, seguida da exploração dos recursos naturais, como madeira e minério, sendo estas as principais fontes de rendas das famílias. A população é estimada em 15.508 habitantes, dos quais $77,85 \%$ residem na zona rural $^{1}$. As características edafoclimáticas e o longo período de estiagem são limitantes às atividades agropecuárias. A maioria dos proprietários rurais se enquadra no perfil de agricultor familiar².

No ano de 2008, a então reativada Secretaria Municipal de Agricultura e Meio Ambiente contava apenas com um engenheiro agrônomo atuando como agente de extensão. Este trabalhava na perspectiva de utilizar a extensão rural como ferramenta de apoio aos agricultores familiares, objetivando colaborar com o desenvolvimento socioeconômico e ambiental do município, para, sobretudo, atenuar a dependência destes em relação às práticas clientelistas comuns no semiárido brasileiro. Apenas após ocorrer certa pressão por parte das representações sociais, e do agente de extensão que já estava atuando, outro agrônomo foi contratado para atuar no município. Os trabalhos preconizados, se contassem com maior apoio do governo local, talvez pudessem ter contribuído para o aumento da qualidade dos serviços. Agrande demanda para apenas um funcionário, juntamente com os baixos investimentos da prefeitura, impossibilitaram a expansão das atividades.

Um conjunto de fatores afeta as práticas socioeconômicas dos agricultores do semiárido. Entre esses, a falta de comprometimento por parte do poder público; a baixa incidência de políticas públicas apropriadas à realidade regional prejudica a geração de renda das famílias e a sustentabilidade das atividades econômicas. Consequentemente, isso potencializa o clientelismo $^{3}$, pois as dificuldades enfrentadas causam dependência da população ao paternalismo dos dirigentes públicos.

Dessa forma, este artigo pretende descrever o processo histórico da extensão rural no país, as novas diretrizes propostas para os trabalhos de Ater, além de contribuir com a discussão sobre o papel da extensão rural como ferramenta de emancipação das

\footnotetext{
${ }^{1}$ Censo demográfico 2010, Instituto Brasileiro de Geografia e Estatística - IBGE

${ }^{2}$ De acordo com a Lei n. ${ }^{\circ} 11.326$, de 24 de julho de 2006.

${ }^{3} \mathrm{O}$ clientelismo, segundo o Dicionário de Sociologia, define-se como exigência da ajuda de outrem para existir plenamente (o cliente), mas supõe, além disso, uma fidelidade relativamente constante (a clientela). Aqui se associa o termo às práticas entre atores políticos e eleitores.
} 
políticas clientelistas. Assim, utilizaremos alguns dos serviços de Ater realizados no município de Ibitiara, como forma de procurar demonstrar, empiricamente, que os agricultores familiares podem obter incremento de renda e melhorar a qualidade de vida de suas famílias, utilizando-se de sistemas produtivos menos impactantes, contribuindo para a redução das dependências causadas pela ineficiência dos governos.

Este trabalho constitui-se de um breve histórico da extensão rural no país e as controvérsias geradas pelo modelo difusionista-inovador. Em seguida, é realizada uma alusão às novas perspectivas extensionistas que emergem no país no fim da década de 1970 e se expandem até os dias de hoje. Posteriormente, faz-se a caracterização do município de Ibitiara e, por fim, descrevem-se alguns trabalhos de extensão rural realizados neste município, entre os anos de 2008 e 2011.

\section{O PROCESSO HISTÓRICO DA EXTENSÃo RURAL NO Brasil E SUAS CONTROVÉRSIAS}

A extensão rural institucionalizou-se oficialmente, no Brasil, a partir de 1948, resultado de convênios firmados entre os governos do Brasil e dos Estados Unidos, principalmente através da American International Association - $\mathrm{AIA}^{4}$ que, inicialmente, implantou em Minas Gerais a primeira experiência de extensão rural do país, com a criação da Associação de Crédito Rural - ACAR (FONSECA, 1985, p.62). Essa experiência teve como referência os trabalhos implantados nos Estados Unidos. A proposta do programa era, basicamente, "modernizar" o campo brasileiro, aumentar a produção e melhorar a condição socioeconômica das populações rurais, conforme cita Fonseca (1985):

Na ótica de tais programas, o objetivo básico era levar as camadas populares rurais ao alcance de duas metas essenciais para a conquista do desenvolvimento econômico-social: a obtenção de melhores índices de produtividade, aliada a uma maior racionalização da produção agrícola e, consequentemente, de melhores condições de vida no campo (FONSECA, 1985, p. 48).

Diante do processo modernizante adotado para a agricultura, a mudança do padrão dos sistemas produtivos entrou como pauta urgente nos processos decisórios. Porém, o cenário econômico do campo não correspondia ao modelo a ser implantado. A pobreza e a baixa produtividade eram realidades já nas décadas anteriores. Segundo Fonseca (1985), para o Estado brasileiro, a causa desses problemas "já não se justificava mais pelo 'despreparo do homem do interior', como no discurso dos anos 20-30, mas simpelas reais condições econômicas sob as quais estavam vivendo o agricultor e sua família" (FONSECA, 1985. p. 73).

Assim, a extensão rural tornou-se condição fundamental para o desenvolvimento agropecuário. Sem o reparo dos desequilíbrios sociais entre campo e cidade, sobretudo, com a constante variação dos preços dos alimentos, o panorama produtivo brasileiro estaria fadado ao fracasso. Dessa forma, a extensão se definia, como um "empreendimento educativo capaz de 'produzir mudanças nos conhecimentos, nas atitudes e nas habitações para que se atinja o desenvolvimento tanto individual como social"' (FONSECA, 1985. p. 91).

Dentro da lógica de produção do complexo agroindustrial, a modernização tinha condicionante para sua eficácia a tecnologia como força produtiva propulsora do desenvolvimento. A extensão rural integrava esse esquema como meio de difusão do saber técnico a uma população do campo com níveis educacionais precários. As possibilidades do baixo entendimento do manejo dos aparatos tecnológicos eram evidentes. Aliado a isso, o crédito rural servia como para viabilizar o acesso à tecnologia, compra de insumos químicos e infraestrutura.

\footnotetext{
${ }^{4}$ Entidade sem fins lucrativos criada nos Estados Unidos que desempenhou importante papel no desenvolvimento da extensão rural.
} 
Para obter sucesso nesta empreitada, os extensionistas foram treinados para persuadir os agricultores a implantar pacotes tecnológicos. Pregava-se a necessidade de uma mudança de hábitos, o que significava a exclusão das práticas agrícolas tradicionais. Consequentemente, os agricultores deveriam implantar um novo padrão técnico, de preferência sem questionar as tecnologias ofertadas e atreladas ao crédito rural, tendo seus conhecimentos empíricos desconsiderados. $\mathrm{Na}$ realidade, o que se desejava era a formação de uma sociedade no campo que além de produzir alimentos, se transformasse em potencial consumidora de produtos industrializados (COELHO, 2005; FONSECA, 1985; FREIRE, 1992).

O difusionismo tornou-se centro de adequação da experiência americana para os países subdesenvolvidos, como o Brasil, tendo Rogers ${ }^{5}$ como principal mentor dessa proposta teórico-metodológica, que ambicionava alcançar a mudança de hábitos por parte das populações locais em menor prazo. Assim, os habitantes de "áreas tradicionais ou subdesenvolvidas" modificariam seus comportamentos passando a adotar "práticas consideradas cientificamente válidas" no intuito de solucionar os problemas locais e alcançar o desenvolvimento socioeconômico almejado pelo governo brasileiro (FONSECA, 1985, p. 46).

Segundo Costa, o difusionismo.

(...) partia de uma concepção didática do tipo "centro-periferia"; na qual, a informação é gerada em um momento do processo de comunicação e depois é transmitida aos receptores. No interior deste processo, não são considerados os valores que permeiam emissores e receptores. Ademais, outro aspecto problemático é a constituição de uma cadeia de dependência unilateral dos receptores/usuários. Isso porque, é privilegiado no processo de "aprendizagem" somente os sistemas de conhecimento do emissor; cabendo aos conhecimentos dos receptores o completo descrédito. $\mathrm{O}$ paradigma culmina em uma relação social subordinada, assimétrica e/ou desequilibrada entre os atores sociais envolvidos (COSTA, 2010, p.5).

\section{Para Caporal e Ramos:}

Por trás desse tipo de extensão rural, que foi dominante ao longo de várias décadas, estava um modelo de desenvolvimento urbano-industrial cuja viabilização necessitava que a agricultura cumprisse funções, entre as quais a de fornecedora de mão-de-obra e de consumidora de serviços e produtos industrializados, como as máquinas, os equipamentos, as sementes híbridas ou melhoradas, os agrotóxicos e fertilizantes químicos sintéticos, além de contribuir, pelas exportações, para o superávit da balança comercial. Esse modelo, que é fruto de decisões políticas, norteou a ação extensionista. Ao mesmo tempo, continua sendo responsável pela concentração da terra, pelo êxodo rural, pela baixa escolaridade no campo, pela redução da biodiversidade, pela poluição, pela contaminação dos alimentos, pela exclusão social, pela desvalorização do trabalho na agricultura, pelo empobrecimento no meio rural, entre outros problemas (CAPORAL \& RAMOS, 2006, p.3).

Ao potencializar os problemas socioeconômicos acima citados, o modelo modernizante, pautado no difusionismo, colaborou para decrescer a qualidade de vida dos agricultores de menor poder aquisitivo e daqueles que não conseguiram, ou não quiseram,

${ }^{5}$ Everett M. Rogers (1931-2004) é conhecido no meio acadêmico como o mentor do modelo difusionista-inovador. Sua obra mais conhecida é Difusão de Inovações, publicada em 1962. Foi professor da disciplina de Difusão na Universidade de Michigan, nos Estados Unidos. Realizou dezenas de pesquisas na Colômbia, Índia, Tailândia e Brasil, contando com o financiamento da UNESCO, Fundação Ford e AID" (FONSECA, 2005, p.42). 
inserir-se nele. Assim, pressupõe-se que este modelo colaborou para a continuidade de práticas clientelistas nos municípios do semiárido, a exemplo de Ibitiara, na Bahia.

Além destas questões, o processo educacional praticado pela extensão rural no Brasil foi questionado por Paulo Freire (1977). Segundo ele,

(...) no processo de aprendizagem, só aprende verdadeiramente aquele que se apropria do aprendido, transformando-o em apreendido, com o que pode, por isso mesmo, re-inventá-lo; aquele que é capaz de aplicar o aprendido-apreendido a situações existenciais concretas. Pelo contrário aquele que é "enchido" por outros de conteúdos cuja inteligência não percebe, de conteúdos que contradizem a própria forma de estar em seu mundo, sem que seja desafiado, não aprende (FREIRE, 1977, p. 13).

Portanto, para que o trabalho de extensão rural atue como processo educacional, faz-se necessário que ocorra a internalização dos conhecimentos adquiridos que, somados aos conhecimentos práticos já possuídos pelos agricultores, tornam-se complementares. Para Paulo Freire, essa é a questão primordial do processo educacional, o entendimento do que é passado não sendo apenas uma reprodução "mecânica". No entanto, da forma que os extensionistas do modelo difusionista atuaram, desconsiderando os conhecimentos práticos dos agricultores, pode acontecer que, em possíveis eventualidades, os agricultores encontrem dificuldades para remediar uma possível situação encontrada, pois estes não interagem entre os conhecimentos repassados pelos extensionistas e o cotidiano, de forma que consigam modificar e adequar o "aprendido", chegando ao ponto do "apreendido" ser considerado nulo.

Freire (1992) entende a extensão rural assim praticada como "invasão cultural", pois a concepção de dominação se faz presente. Em contrapartida, o processo educacional deve ser visto como forma libertadora do homem, não o homem inerte dentro do processo, mas "em sua interação com a realidade, que ele sente, percebe e sobre a qual exerce uma prática transformadora" (FREIRE, 1977, p.75).

Devido às críticas e aos problemas oriundos desse modelo modernizante, aAter pública no Brasil começou a ser repensada. Um novo modelo para a extensão rural brasileira iniciou-se, preconizando o "estabelecimento de uma relação dialética entre o agricultor e o extensionista", que visa à construção de conhecimentos apropriados a cada realidade, além da troca de saberes como forma de diagnosticar e buscar soluções para os problemas locais (CAPORAL e RAMOS, 2006, p.4).

\section{AS NOVAS PERSPECTIVAS DA EXTENSÃo RURAL}

Após vários debates, questiona-se qual a melhor forma de se praticar a extensão rural. Passa-se a percebê-la dentro de uma nova perspectiva, entendendo-a como troca de conhecimentos acadêmicos e empíricos entre extensionistas e agricultores. Envolvem-se no processo as questões sociais, culturais, tradicionais, buscando o respeito à forma de viver e pensar dos agricultores. Agora, dentro do processo de extensão, estes têm o direito de expressar suas vontades, seus anseios e não servir meramente de expectadores para as orientações dos técnicos.

Juntos, extensionistas e agricultores, conscientemente, devem identificar problemas e procurar soluções. Essa busca deve perpassar o campo da agropecuária, e abranger "os níveis político, social, ambiental, econômico, cultura e ético" (CAPORAL \& RAMOS, 2006, p.6-7).

Portanto, deve-se desconsiderar a concepção de que os técnicos, por possuírem conhecimentos acadêmicos, sejam agentes que detêm saberes maiores que os homens do campo. Não existe saber maior ou menor, o que existe são conhecimentos e práticas diferentes que devem ser somados para que se possa realizar uma extensão rural que traga vantagens e corresponda aos anseios das populações rurais.

Embasado nessa nova concepção de Ater, no ano de 2003, o Ministério do Desenvolvimento Agrário coordenou a formulação da Política Nacional de 
Assistência Técnica e Extensão Rural-PNATER. Esta tinha por preceito as perspectivas trazidas pelo novo modelo de extensão rural: valorização dos saberes locais, mudança na forma de atuar dos extensionistas e das instituições de Ater, etc. Assumindo um posicionamento que busca potencializar o uso de metodologias educativas e participativas, com o exercício de uma gestão descentralizada, possibilitando a participação social, viabilizando a prática e o fortalecimento da cidadania.

No intuito de fazer com que os processos produtivos sejammenos impactantes, o documento da política, formulado a partir de 2003, alega a necessidade da transição do modelo convencional para um novo modelo, o agroecológico. Dessa forma, a Ater pública deveria colaborar para o desenvolvimento rural sustentável preconizado pela PNATER.

As mudanças de conduta por parte das instituições estatais responsáveis pela extensão rural devem ter como um dos princípios a adoção da metodologia participativa na busca do desenvolvimento rural do país, trazendo características endógenas na identificação dos problemas e das suas possíveis soluções (SILVA, 2010).

Porém, diante dessa nova empreitada, podem surgir algumas dificuldades que, em caso de surgimento, precisam ser superadas. APNATER elenca a necessidade de mudança por parte das empresas de Ater em relação às burocracias internas e ao trabalho desenvolvido por seus técnicos, no que tange as diretrizes, normas e metas que precisam ser cumpridas por estes. Dessa forma esta mudança pode não ser comprida inviabilizando a implantação deste novo modelo de ATER.

A partir da necessidade de mudanças de postura dos técnicos e das instituições que fazem a extensão rural, Caporal e Ramos (2006) descrevem:
Nesse sentido, o esforço de mudança é duplo, pois significa refletir sobre a própria prática e tomar decisões sobre seu papel, sua forma de atuação e, ao mesmo tempo, contribuir para a redefinição das estruturas e das relações de poder vigentes nas organizações de Ater. (CAPORAL \& RAMOS, 2006, p.6)

Acompanhando essa nova visão, surgiu o direcionamento dos trabalhos para a agroecologia, que busca aliar a melhora socioeconômica das famílias rurais a atividades menos impactantes, enfatizando a produção de alimentos mais saudáveis, de melhoras nos hábitos alimentares e respeitando as tradições e culturas locais, de acordo comPetersen, Dal Soglio e Caporal (2009).

O enfoque agroecológico possibilitou a ampliação do escopo da abordagem dos problemas rurais, contribuindo para o questionamento do viés produtivista das ciências agrárias e para a mobilização do interesse e do engajamento de setores das ciências humanas e naturais na construção do novo paradigma (PETERSEN; DAL SOGLIO; CAPORAL, 2009, p.85).

Após seis anos da publicação do documento da PNATER, no ano de 2010, é aprovada a lei que a institui ${ }^{6}$. Este novo documento, se comparado ao de 2004, possui uma menor ênfase em relação à agroecologia, referindo-se apenas que é necessária a adoção de "princípios da agricultura de base ecológica". Segundo Caporal (2011), a reformulação da PNATER teve como pressuposto, sob o ponto de vista dos gestores, "estabelecer mecanismos mais ágeis (...) de modo a facilitar tanto a operacionalização interna do MDA, como a forma de prestação de contas das entidades de Ater...", mas para o autor não foi apenas

${ }^{6}$ Lei 12.188, de 11 de janeiro de 2010. Institui a Política Nacional de Assistência Técnica e Extensão Rural para a Agricultura Familiar e Reforma Agrária - PNATER e o Programa Nacional de Assistência Técnica e Extensão Rural na Agricultura Familiar e Reforma Agrária - PRONATER, altera a Lei n. ${ }^{\circ}$ 8.666, de 21 de junho de 1993, e da outras providências. A Lei n. ${ }^{\circ}$ 8.666 é responsável por instituir normas para licitações e contratos da Administração Pública. 
isso que ocorreu. Para ele, o novo documento contraria o de 2004, excluindo a agroecologia de seu texto e desrespeitando o processo participativo ocorrido entre 2003 e 2004.

A Lei de 2010 possui semelhanças nos princípios trazidos pelo documento de 2004, como exemplo: busca do desenvolvimento rural sustentável; adoção de metodologias participativas; a gratuidade e a busca da qualidade e da acessibilidade para os serviços públicos de ater.

Como formulação do poder público, a PNATER deve ser o norte dos trabalhos de extensão rural no Brasil para as entidades que pretendem acessar seus recursos. Foi procurando atuar de acordo com a Lei de 2010, no intuito de colaborar com a melhora socioeconômica dos agricultores familiares, e na busca de alternativas de processos produtivos menos impac-tantes, que se buscou pautar os trabalhos de Ater em Ibitiara.

\section{O MUNICÍPIO DE IBITIARA}

O município dista $535 \mathrm{~km}$ da capital do Estado, Salvador, e está localizado na região denominada Chapada Diamantina no semiárido baiano (Figura 1). Possui área de 1.748,85km2, clima subúmido a seco, temperatura média anual de $21,6^{\circ} \mathrm{C}$ e pluviosidade anual de $746 \mathrm{~mm}$, um total de 4.220 domicílios e 2.181 famílias beneficiadas com o programa Bolsa Família. (SEI, 2011).

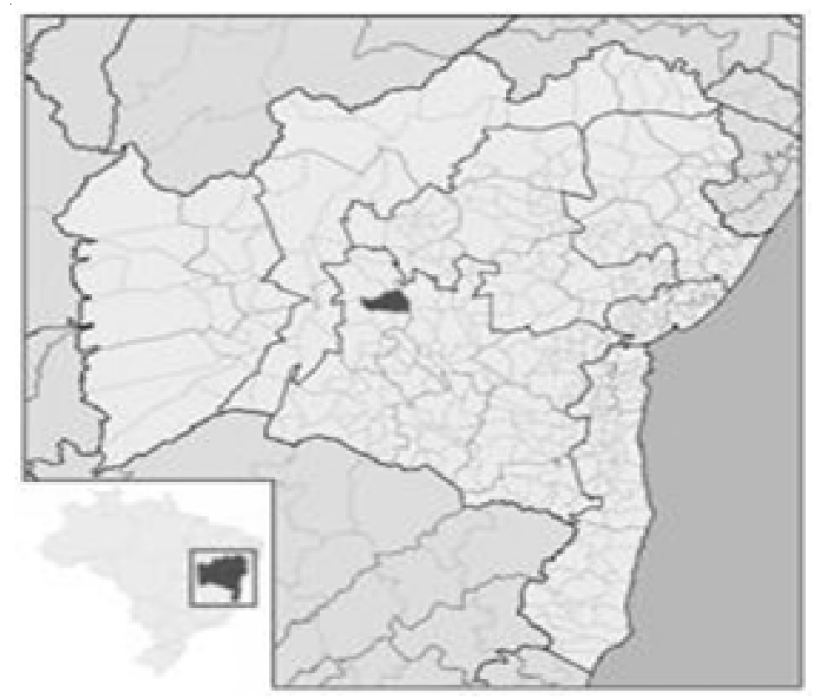

Figura 1 - Localização do Município de Ibitiara.

Fonte: pt.wikipedia.org

Dentre os índices de desenvolvimento social, de acordo com dados da Superintendência de Estudos Econômicos e Sociais da Bahia (SEI, 2011), destacamos três, os quais retratam a realidade municipal, em comparação com os outros 416 municípios do Estado:

1) Índice dos Serviços Básicos - ocupa a 334. ${ }^{a}$ posição no ranking estadual;

2) Índice de Renda Média Anual dos Chefes de
Família: R \$ 4.928,27 - 354. ${ }^{\mathrm{a}}$ posição;

3) Índice de Desenvolvimento Social - ocupa a 262. a posição.

Em relação ao PIB (em milhões) municipal no ano de 2008, a Indústria aparece com total de R \$ 4,22; a agropecuária, com $\mathrm{R} \$ 4,45$; e o setor de serviços, que inclui a administração pública e as atividades governamentais, com R \$ 31,91 (SEI, 2011). 
De acordo com os dados do Programa das Nações Unidas para o Desenvolvimento - PNUD (2000), quando a população total do município era de 14.443 habitantes, 42,2 \% da população (6.095 habitantes) era considerada indigente; $30,9 \%$ era considerada pobre, o que na época equivalia a 4.461 habitantes; restando apenas 3.887 habitantes, ou $26,9 \%$ da população total, fora da linha da pobreza (Figura 2).

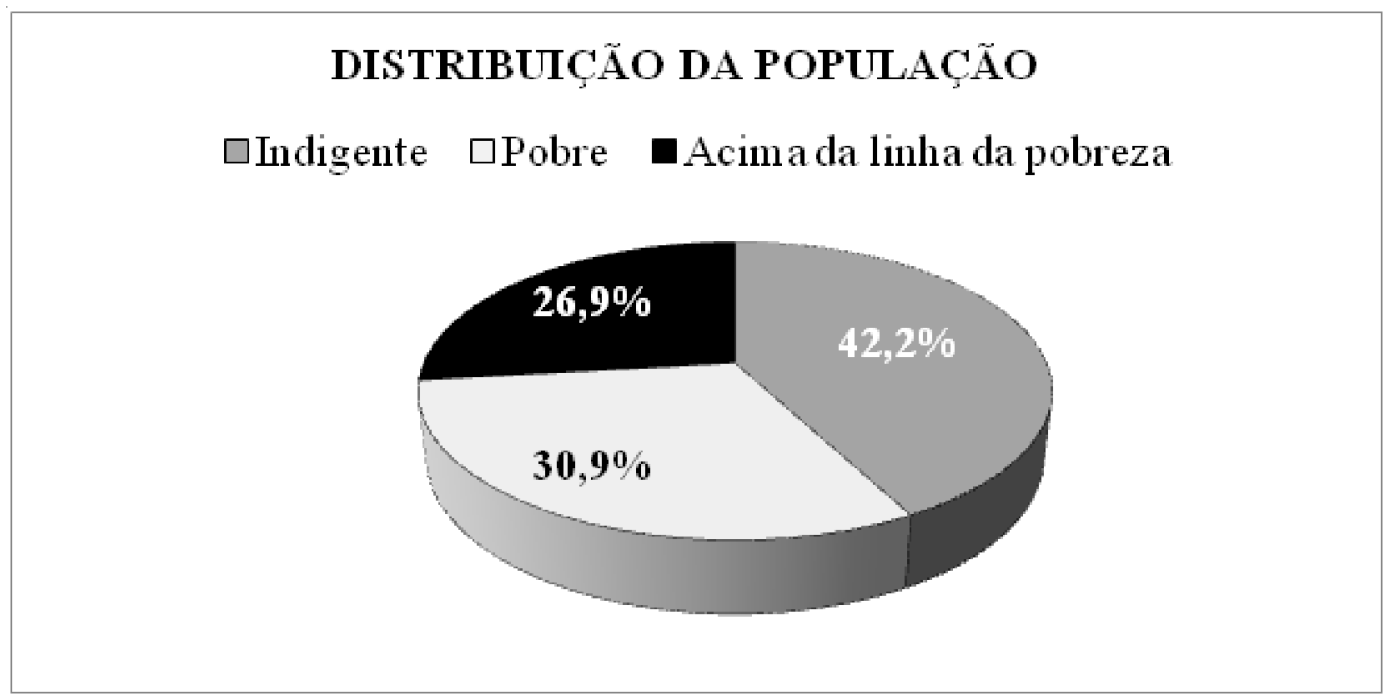

Figura 2 - Distribuição da população.

Fonte: PNUD (2000).

A população tem nas atividades agropecuárias o sustento de suas famílias, porém, devido às dificuldades de melhora socioeconômica e até da produção com vista à subsistência, os agricultores familiares se veem obrigados a buscar alternativas para sobrevivência. Estas são altamente impactantes do ponto de vista ambiental, pois se concentram na exploração da flora, principalmente da madeira para produção de carvão vegetal e estacas, e nos garimpos ilegais.

$\mathrm{Na}$ produção de carvão vegetal, os habitantes locais são estimulados, na sua grande maioria, por compradores e caminhoneiros do Estado de Minas Gerais que transportam o carvão para siderúrgicas mineiras. Os garimpos são explorados por jovens e por pais de famílias que buscam o complemento financeiro para o sustento familiar. Parte dos jovens envolvidos nessas atividades deixa de frequentar a escola e muitos decidem migrar para outras regiões do país.

Muitas pessoas vendem a força de trabalho para sobreviver, trabalhando de diaristas em propriedades maiores, como pedreiros ou serventes dentro ou fora do município, ou em eventuais atividades realizadas pela própria prefeitura.

Nesse aspecto, as vidas são expostas ao perigo nas atividades acima citadas, pois não é utilizado nenhum tipo de equipamento de proteção individual e não existe nenhum tipo de capacitação, além dos riscos de doenças que podem ser adquiridas por materiais poluentes, oriundos dessas atividades.

Essa situação se agrava, uma vez que os trabahadores não são organizados. Percebe-se que muitos não possuem noção do valor do produto que estão comercializando, ficando vulneráveis às explorações de atravessadores, os quais põem o preço das mercadorias à venda. Essa desorganização pode ser entendida devido a fatores que são descritos por Tonneau e Cunha (2005), ao pesquisarem sobre o conceito de territórios e sua relação com o desenvolvimento sustentável no semiárido nordestino. 
Devido a fatores econômicos (falta de recursos, pobreza, desemprego); sociais (dependência, subordinação); geográficos (isolamento, comunicações, limitantes naturais); educacionais (educação formal deficiente, analfabetismo, baixa informação e capacitação) e práticas políticas (pouca participação, clientelismo), a complexidade das situações de não-desenvolvimento faz com que grande parte dos atores, sobretudo os segmentos sociais que constituem o que se poderia denominar de sociedade civil não-organizada... (TONNEAU, CUNHA, 2005)

As atividades acima citadas não são legalizadas e, tampouco, fiscalizadas. O poder público municipal se omite em resolver esses problemas, sobretudo, pouco investe para potencializar os serviços de Ater. As famílias possuem limitadas alternativas para desenvolver atividades que possibilitem seu sustento.

Os trabalhos de extensão rural foram pontuais e derivaram da força de vontade e do comprometimento dos extensionistas e das reivindicações dos movimentos sociais que buscaram se organizar. Estes, possivelmente, foramos motivos que colaboraram no convencimento do poder público em investir nesse tipo de projeto. Porém, essa situação, aparentemente, não retratou uma mudança de visão por parte dos políticos locais atuantes na época em questão.

O cenário acima exposto dificulta ainda mais a sobrevivência da população, aumenta o êxodo rural no município e desestimula o agricultor familiar na permanência das atividades agropecuárias. Dessa maneira, a pluriatividade se desenvolve como alternativa econômica a essas famílias, porém, de forma não sustentável, podendo ser entendida, segundo Schneider (2003)

(...) como um fenômeno através do qual membros das famílias de agricultores que habitam no meio rural optam pelo exercício de diferentes atividades, ou mais rigorosamente, optam pelo exercício de atividades não agrícolas, mantendo a moradia no campo e uma ligação, inclusive produtiva, com a agricultura e a vida no espaço rural (SCHNEIDER, 2003, p.91).

\section{A EXTENSÃo RURAL EM IbITIARA}

A Secretaria Municipal de Agricultura e Meio Ambiente de Ibitiara, no ano de 2008, contava com apenas um engenheiro agrônomo, atuando como extensionista. Ainda em 2008, a Prefeitura Municipal formalizou um convênio de cooperação técnica com a Empresa Baiana de Desenvolvimento Agrícola EBDA. Porém, a parceria ficou aquém do esperado, uma vez que a empresa passava por um processo de reformulação, dificultando a locação de recursos no município. Essa parceria possibilitou a utilização de veículos da EBDA, material de escritório, cursos de capacitação e pagamento de diárias para os técnicos do convênio, já que, em 2009, a prefeitura contratou outro agrônomo para atuar no município, em parceria com a EBDA.

Essa contratação ocorreu, principalmente, devido ao fato, descrito anteriormente, de que os movimentos sociais, por meio do Sindicato dos Trabalhadores e Trabalhadoras Rurais, do Fundo Municipal de Apoio Comunitário - FUMAC e de alguns presidentes de Associações, buscaram se organizar e cobrar da prefeitura municipal melhora e ampliação dos trabalhos que estavam sendo realizados no município. Dessa forma, os trabalhos de Ater também ajudaram a desenvolver a então ínfima organização social existente até aquele momento.

No ano de 2010, o convênio com a EBDA possibilitou a chegada de dois técnicos agrícolas, totalizando, assim, quatro extensionistas. A secretaria municipal não possuía nenhum tipo de orçamento financeiro próprio, dificultando ainda mais os trabalhos, já que os poucos recursos financeiros disponibilizados eram diretamente liberados pelo gestor, mediante pedido, acompanhado de explicações por parte dos técnicos.

As ações extensionistas que obtiveram algum destaque demonstraram ser possível melhorar a qualidade de vida da população, sobretudo, através de técnicas apropriadas às realidades locais e construídas de forma participativa com os beneficiários 
da Ater pública municipal.

As atividades foram desenvolvidas a partir de visitas a algumas comunidades rurais. A princípio, realizaramse reuniões no intuito de levantar, de forma participativa, os obstáculos para o desenvolvimento das atividades responsáveis pelo sustento das famílias e dos demais anseios das comunidades.

Na ótica dos técnicos envolvidos comos trabalhos em Ibitiara, a extensão rural foi abordada sob o viés libertador do clientelismo, historicamente praticado no semiárido, visto como obstáculo ao desenvolvimento regional. Clientelismo que pode ser considerado como responsável pela criação da "cultura da subalternidade", apontada no semiárido paraibano e descrita por Oliveira \& Duque (2004).

Mas nossa identificação dos obstáculos que se opõem ao desenvolvimento sustentável do SemiÁrido vai além disso tudo. Ou melhor, se situa num patamar cronologicamente anterior, numa pré-condição que impede a obtenção dessas condições mínimas, numa situação criada que explica na maioria das vezes o "abandono" (para adotar a expressão popular local) das populações rurais da região. Estamos nos referindo ao que chamaríamos de "cultura da subalternidade", reforçada por uma relação individual de dependência vertical, contrária às formas horizontais de organização. Herança da escravidão e do coronelismo, essa "cultura" mantém as populações numa relação de dependência em relação ao poder local, seja ele representado pelo grande proprietário, pelo "chefe" político, pelo poder municipal ou estadual. O binômio: "Um favor - um voto" continua imperando, dando continuidade ao "poder dos donos" (OLIVEIRA \& DUQUE, 2004).

É essa "cultura da subalternidade" que os agentes de extensão rural em Ibitiara quiseram amenizar através da extensão rural.

$\mathrm{Na}$ interpretação desses extensionistas, o campo não deveria ser visto apenas como uma área de produção. Constituindo-se em uma sociedade, com proble- mas análogos a qualquer sociedade citadina, seja de cunho político, social, cultural, agrícola, ambiental, etc. Portanto, nas reuniões, buscava-se ouvir a população e levantar os problemas das comunidades trabalhadas, independente da área: educação, saúde, agropecuária, abastecimento de água, etc. Posteriormente, essas informações eram repassadas às outras secretarias municipais, para que cada setor responsável buscasse amenizar ou resolver os problemas descritos.

Salienta-se que, devido à formação dos extensionistas, seus trabalhos eram pautados, em sua quase totalidade, na agropecuária, e que a prática acima exposta retrata o interesse em minimizar esse efeito. Seguindo a perspectiva trazida por Abramovay (1998), quando cita a discussão dos grupos de trabalho que participaram do "Seminário Nacional de Assistência Técnica e Extensão Rural: uma nova extensão para a agricultura familiar", realizado em Brasilia no ano de 1998, em que, segundo o autor, a missão da ATER já era entendida pelos participantes do evento de uma forma mais ampla, que não ficasse ligada apenas aos sistemas produtivos.

A leitura dos relatos dos grupos mostra que não se trata apenas de voltar-se para o "agroagrícola" e confinar-se a tarefas de natureza estritamente produtiva (embora estas sejam evidentemente centrais na vida, no dia a dia do extensionista), mas de inserir sua ação numa luta mais ampla: todos os grupos que trataram da missão falaram de cidadania, de desenvolvimento sustentável, de participação, de ampliação de acesso ao conhecimento, e ao mercado e de livre organização. (ABRAMOVAY, 1998, p. 147)

Por meio da participação social, a Secretaria Municipal de Agricultura e Meio Ambiente de Ibitiara elaborou, no ano de 2008, quatro Planos Municipais no intuito de nortear os trabalhos de extensão rural no município. Estes possuíam os seguintes temas: agricultura, pecuária, meio ambiente e convivência com a seca. É importante observar que esse planejamento foi elaborado após o técnico enumerar, em conjunto 
com representantes das comunidades, os principais problemas e as possíveis soluções para os mesmos. Após a formulação, os planos foram apresentados em algumas comunidades e em reunião com o FUMAC, onde estava presente a maioria dos 48 presidentes das associações municipais, para depois serem entregues ao prefeito.

Conforme citado anteriormente, a secretaria municipal não possuía recursos financeiros próprios e, portanto, as atividades propostas foram implantadas apenas em algumas comunidades, não sendo possível oportunizá-las para as demais.

Cada plano propunha que um determinado percentual do Fundo de Participação dos Municípios fosse repassado para desenvolver respectivamente suas atividades. Porém, esse item foi ignorado pelo poder público municipal, que argumentava não possuir verba financeira suficiente para implantá-los. Com isso, apenas alguns trabalhos elencados nos planos puderam ser operacionalizados, utilizando os poucos recursos disponibilizados pela prefeitura municipal.

Mesmo com esse baixo suporte do poder público, as atividades continuaram a ser desenvolvidas no campo. Além disso, os membros da Secretaria de Agricultura e Meio Ambiente, juntamente com os técnicos fornecidos pelo convênio com a EBDA, trabalharam no âmbito escolar, realizando palestras para os estudantes - a maioria deles filhos de agricultores e moradores do campo. A temática abordada incluía assuntos pertinentes à realidade dos alunos e de suas famílias no desenvolvimento das suas atividades econômicas, englobando-as dentro da perspectiva da sustentabilidade. Assim, suas dúvidas e questionamentos relacionados ao cotidiano das atividades eram debatidos nas salas de aulas. Os estudantes também eram incentivados a repassar os novos conhecimentos às famílias e produzirem em casa hortas e pomares orgânicos para consumo próprio e, se de interesse, para venda do excedente.

Somado a isso, montaram-se parcerias com outras instituições, no intuito de ofertar a esses agricultores familiares cursos de capacitação dentro das perspectivas que foram levantadas nos planos municipais. Além da Empresa Baiana de Desenvolvimento Agrícola EBDA, o Serviço Brasileiro de Apoio às Micro e Pequenas Empresas - SEBRAE também se envolveu nesse projeto. Junto a isso, foram realizados cursos e palestras no intuito de esclarecer sobre a importância do associativismo e para implantação de técnicas sustentáveis de convivência com o semiárido, possibilitando ao agricultor relatar suas experiências e participar na construção das alternativas juntos aos técnicos extensionistas.

Dentre as experiências vivenciadas nessas atividades, vale destacar que um grupo de agricultores se interessou pelo beneficiamento de frutas. A partir disso, os técnicos entraram em contato com uma associação de beneficiamento de frutas existente no município de Brotas de Macaúbas, na Bahia. Duas das agricultoras do grupo foram ao povoado de Lagoa de Dentro, no município de Ibitiara, e ministraram um curso para os interessados. No total, 22 pessoas participaram do curso; destas, 12 resolveram montar um agrupamento para continuar com o trabalho, porém apenas 8 continuaram. Essas atividades foram realizadas principalmente com o aproveitamento de espécies nativas, como o umbu (Spondias Tuberosa Arruda) e o maracujá do mato (Passiflora Cincinatta).

Os agricultores e agricultoras, desde então, se reuniam para realizar o beneficiamento, tendo como principais produtos: doces, geleias e polpas. A comercialização inicialmente foi realizada com a Prefeitura Municipal de Ibitiara, através do Programa Nacional de Alimentação Escolar - PNAE, com possível ampliação da rede de comércio. O grupo de beneficiamento de frutas não possuía sede própria, mas utilizava o espaço físico da associação comunitária do povoado de Lagoa de Dentro para a realização dos trabalhos, já que todos os membros faziam parte dessa associação. Parte dos recursos financeiros, oriundos das vendas, foi utilizado para a compra de utensílios que possibilitaramo aperfeiçoamento da produção; a outra parte era dividida entre os participantes.

É importante salientar que existem no município de Ibitiara quatro comunidades quilombolas (Capão, Caraíbas, Vila Nova e Cana Brava), com tradição no 
cultivo da mandioca. $\mathrm{O}$ beneficiamento dessa cultura consistia, basicamente, na produção da farinha e da tapioca, ficando os agricultores familiares à mercê dos atravessadores. Na busca para amenizar a atuação destes e diversificar os subprodutos oriundos do beneficiamento da mandioca, a parceria com o SEBRAE mostrou-se eficiente junto aos quilombolas. Foram ofertados aos agricultores familiares de três dessas comunidades (Capão, Caraíbas, Vila Nova) cursos na área de culinária e assessoria, para que começassem a acessar políticas públicas para agricultura familiar.

No Capão, oito agricultoras participaram dos cursos; após a realização deles, todas se agruparam e começaram a produção e venda, porém, apenas quatro continuaram. Em Caraíbas, 12 agricultoras fizeram o curso, porém apenas 8 delas montaram um grupo para produção e venda. Na Vila Nova, 23 participaram, mas, em razão de diversos conflitos no processo de instalação do grupo, a comunidade desistiu de realizar as atividades.

As duas comunidades que estavam produzindo, Capão e Caraíbas, contaram com apoio inicial dos extensionistas e da Prefeitura Municipal de Ibitiara. Esses grupos se organizarame conseguiram acessar políticas públicas: O Programa Nacional de Alimentação Escolar-PNAE, tendo, por esse motivo, a prefeitura municipal como principal compradora; e o Programa Aquisição de Alimentos - PAA, da Secretaria de Desenvolvimento Social e Combate a Pobreza - SEDES, programa desenvolvido em parceria entre o governo da Bahia e o governo federal, além de continuarem comercializando em feiras livres no município e em outras cidades da região, amenizando, assim, a dependência dos atravessadores.

A farinha e a tapioca ainda eram os principais produtos e os atravessadores continuaram a ser os principais compradores, porém, com a realização desses trabalhos, alguns agricultores começaram a diversificar a produção e a buscar outros mercados.

Foi desse modo que os técnicos de Ater do município e os agricultores familiares envolvidos nos trabalhos buscaram formas de aumentar a produtividade local e de alcançar alternativas de comercialização para seus produtos no mercado local e regional.

Baseado nos conhecimentos dos agricultores ibitiarenses sobre pecuária e nos hábitos alimentares dos rebanhos, os extensionistas procuraram colaborar na atividade, através da realização de cursos para produção de feno e silo. Por conhecerem a importância nutricional da leucena (leucenaleucocephala) na alimentação dos rebanhos, devido ao seu alto índice de proteínas, do seu importante papel como fixadora de nitrogênio no solo, sobretudo, da sua grande resistência aos períodos de estiagem, estimulou-se a implantação de bancos de proteínas como uso dessa planta. O objetivo dessa ação foi produzir alimentos para época da estiagem, reduzindo os custos com a compra de ração.

Com seus conhecimentos empíricos somados aos adquiridos nos cursos, os agricultores começaram a utilizar também a vegetação nativa, abundante nas épocas de chuva, para produção de ração, armazenando e ofertando aos animais, no período seco. Com o início das atividades, alguns agricultores se motivaram e ampliaram, dentro das suas possibilidades, as áreas de cultivo da palma (Opuntia fícus indica) e capim buffel (Cenchrus Ciliaris). Comisso, esperava-se uma melhora, no processo de produção pecuário.

\section{CONSIDERaÇões Finais}

O governo brasileiro adotou os serviços de extensão rural, pautados no modelo difusionista, como parte da política de modernização da agropecuária nacional. Esse modelo conseguiu atingir, ainda que não totalmente, seus objetivos: fornecimento de matériaprima para os pólos agroindustriais e formação no campo de uma classe consumidora de produtos industrializados. Porém, também foi responsável por diversos problemas de cunho socioeconômicos e ambientais.

As novas perspectivas adotadas no país para os serviços de extensão rural demonstram avanços. Com a criação da Política Nacional de Assistência Técnica e Extensão Rural, que deve nortear a Ater brasileira, percebe-se a valorização aos conhecimentos tradicionais e aos saberes locais; além de instituir a descentra- 
lização da gestão da política pública por parte das instituições responsáveis pela Ater, promovendo assim, a possibilidade da participação social e o exercício da cidadania.

No município de Ibitiara pode-se observar que os trabalhos de Ater possibilitaram, ainda que de forma pontual, já que, devido aos poucos investimentos, não foi possível expandir os trabalhos, uma melhora socioeconômica das famílias envolvidas nas atividades de Ater da Secretaria Municipal de Agricultura e Meio Ambiente. Esses trabalhos demonstraram a viabilidade da extensão rural como ferramenta contra as políticas clientelistas, tão comumente utilizadas no semiárido, além de fortalecer o viés da extensão rural como protagonista de ações que amenizam o clientelismo e possibilitam o desenvolvimento da organização social.

Constatou-se a falta ou a insuficiência das ações por parte dos governos, seja municipal ou estadual, para o apoio a trabalhos que buscassem a melhora socioeconômica e ambiental das populações do campo. Também é notável a escassa elaboração de projetos que visassem angariar recursos financeiros em âmbito federal, por parte da Prefeitura Municipal de Ibitiara, para que se pudesse ampliar a quantidade de agricultores familiares a serem beneficiados comos serviços de Ater.

Foi percebida a necessidade para que o gestor ampliasse suas ações e agisse de acordo com as realidades sociais, econômicas e ambientais do município e, assim, satisfazer as verdadeiras necessidades e os anseios da população, seja na busca por investimentos nos setores produtivos, que possibilitariam a diminuição das práticas clientelistas, ou nos demais setores essenciais para a população, como saúde e educação. Essa mudança de postura, se adotada, poderia contribuir, entre outras coisas, para a ampliação dos trabalhos de Ater, objetivando o aumento da qualidade de vida da população e a melhora do município nos âmbitos socioeconômicos e ambientais.

\section{REFERÊNCIAS}

ABRAMOVAY, R. Agricultura Familiar e Serviço Público: novos desafios para a extensão rural. Disponível em:http: //seer.sct.embrapa.br/ index.php/ cct/ article/view/8932. Acesso em 02 jun. 2013

BOUDON, R.; BESNARD, P.; CHERKAOUI, M. e LÉCUYER, P. Dicionário de Sociologia.

Tradução por Ribeiro, A. J. P. Publicações Dom Quixote, LISBOA, 1990.

BRASIL. Ministério do Desenvolvimento Agrário. Política Nacional de Assistência Técnica e Extensão Rural. Brasília, DF: SAF; Dater, 2004. Disponível em: http://www.mda.gov.br/portal/saf/ arquivos/view/ater/Pnater.pdf. Acesso em: 10 março. 2013.

BRASIL. Ministério do Desenvolvimento Agrário. Lei n. ${ }^{\circ}$ 12.188, de 11 de janeiro de 2010. Disponível em: http://www.mda.gov.br/portal/ institucional/novaleideater. Acesso em: 8 mar. 2013.

CAPORAL, Francisco Roberto; RAMOS, Ladjane de Fátima. Da Extensão rural convencional à Extensão rural para o desenvolvimento sustentável: enfrentar desafios para romper a inércia. Brasília: [s.n.], 2006. 23p. Disponível em: http://www.agroeco.org/socla/archivospdf/ Da\%20Extenso\%20Rural\%20Convencional\% 20\%20Extenso\%20Rural\%20para.pdf. Acesso em: 20 nov. 2012.

CAPORAL, Francisco Roberto. Lei de Ater: exclusão da Agroecologia e outras armadilhas. Agroecologia e Desenvolvimento Rural Sustentável, v. 4, n. 1, Ago/Dez, 2011. Porto Alegre: EMATERRS-ASCAR. pp.23-33. 2011. Disponível em:. http://pt.scribd.com/doc/68255334/LEI-DE-ATEREXCLUSAO-AGROECOLOGIA-E-OUTRASARMADILHAS-FRANCISCO-R-CAPORAL. Acesso em: Acesso em: 20 março. 2013.

COELHO, France Maria Gontijo. A arte das orientações técnicas no campo: concepções e 
métodos. Viçosa: UFV, 2005.

COSTA, Klenio Veiga. A extensão rural como preservação da Natureza: uma breve reflexão sobre a ambientalização das políticas públicas de extensão CONGRESSO LATINOAMERICANO DE SOCIOLOGÍA RURAL,8., 2010, Anais... Porto de Galinhas, 2010.

FONSECA, Maria Teresa Lousa. A Extensão rural no Brasil, um processo educativo para o capital. São Paulo: Edições Loyola, 1985.

FREIRE, Paulo. Extensão ou comunicação? 10.ed. Rio de Janeiro: Paz e Terra, 1992.

INSTITUTO BRASILEIRO DE GEOGRAFIAE ESTATÍSTICA - IBGE. Censo demográfico da Bahia. Rio de Janeiro: 2000. Disponível em: http:// www. ibge. gov.br/home/estatistica/populacao/ sinopse_preliminar/Censo2000sinopse.pdf. Acesso em 15 de abril de 2013.

OLIVEIRA, M. S. L.; Duque, G. A Importância dos Fundos Rotativos Solidários para o Desenvolvimento Sustentável do Semiárido Paraibano. Disponívelem: http://www.inicepg. univap.br/cd/INIC_2004/trabalhos/epg/pdf/EPG7- 4.pdf. Acesso em: 17 abril. 2013.

PETERSEN, Paulo. DAL SOGLIO, Fábio Kessler e CAPORAL, Francisco Roberto. A construção de uma ciência a serviço do campesinato. In: PETERSEN, Paulo (org). Agricultura familiar camponesa na construção do futuro. Rio de Janeiro: AS-PTA, 2009, p. 85-104.

SEI - Superintendência de Estudos Econômicos e Sociais da Bahia. Estatística dos municípios baianos. Salvador: SEI, v. 15, 2011.434p. Disponível em: http://www.sei.ba.gov.br/images/publicacoes/ download/estatisticas_municipios/ est_munba_2011_v15.zip. Acesso em 20 abr. 2013.

SCHNEIDER, Sergio. A pluriatividade na agricultura familiar. Porto Alegre: UFRGS, 2003.

SILVA, Danielle Wagner. A Extensão rural entre discursos e práticas. ENCONTRO DA REDE DE ESTUDOS RURAIS.,4, 2010.

Anais...Curitiba, 2010.

TONNEAU, J. P.; CUNHA, L. H. Pesquisas em Desenvolvimento Territorial no Semiárido. Raízes, Campina Grande, v. 24, n.1-2, p. 45-53, jan./dez. 2005

RECEBIDO EM 16/7/2013

Aсегто Eм 21/10/2013 